\title{
The Estimation of the Potential Human Capital Accumulation Rate of China in the Future
}

\author{
Jingru Ren ${ }^{1, *}$, Yu Zhao ${ }^{2}$ \\ ${ }^{1}$ Shenzhen Institute of Information Technology, Shenzhen 518172, China \\ ${ }^{2}$ Wuhan University, Wuhan 430072, China; \\ *Correspondence Author, jingrur124@outlook.com
}

\begin{abstract}
From the perspective that the change in population age structure could affect human capital accumulation, this paper introduces a concept of "the potential growth speed in human capital stock" and discusses the future of China's human capital growth from different aspects. This paper uses the perpetual inventory method and China's sixth national population census data to predict the maximum potential space for China's human capital stock growth in the future. Firstly, we use the average years of schooling of the working-age population as an index to measure the human capital stock. Though decomposing the differences in human capital stock, we introduce the concept of potential growth speed in human capital stock. Secondly, by decomposing accumulation rate of human capital stock in China, differences of human capital stock between China and South Korea, and differences of human capital stock between China and Japan, this paper finds that the age structure change will have a negative factor on China's accumulation of human capital in the next 20 years. To conclude, China will probably accumulate human capital at a much faster rate until 2040, but the human capital growth potential is fully exploited on the condition of that.
\end{abstract}

Keywords: Human capital, The average education attainment of the population, Age structure, The perpetual inventory method.

\section{Introduction}

According to the latest one-percent national sample census in China, China's working-age population has a downward trend in the proportion of the total population and absolute size, showing that the age structure advantage of China's economic development is weakening, the demographic dividend is gradually disappearing. If the demographic dividend is a crucial favorable condition for the rapid growth of China's economy[1-3], the accelerated development of population aging will undoubtedly have a negative impact on China's future economic development. Under the context of accelerating population aging, some Chinese scholars[4-6] suppose that accelerating the increase of human capital stock is one of the most effective ways for China to reduce the negative impact of population aging on economic development and achieve sustainable economic development.

There is a huge gap between China's current human capital stock and that of developed countries[7]. That's why many scholars believe that China can make population change beneficial to economic development by promoting the rapid growth of human capital stock in the future[4-5,8]. However, though the gap between China and developed Countries exists, it doesn't mean human capital stock can increase rapidly. Barro \& Lee[9] estimated the population of different countries according to their age and educational background from 1950 to 2010. Their research finds that the average educational year of the working-age population of Japan in 1970 and China in 2010 was 8.25. The average educational year of Japan from 1970 to 2000 has grown by 0.58 years per year, while Barro \& Lee[10] predict that the average educational year in China from 2010 to 2040 will increase by an average of 0.44 years every five years, a figure that is lower than China's previous 20-year growth rate. Therefore, how much room for increment in China's human capital stock in a certain period remains a problem worth further studying.
Human capital can be defined as the knowledge, skills, abilities, competencies and attributes embodied in individuals that facilitate the creation of personal, social and economic well-being[11]. Human capital and physical capital is different, the most significant differences between them are that human capital is carried by human while the physical capital is carried through production. Regardless of the "cost-based approach," "income-based approach," or "indicators-based approach" used to measure human capital, there is an upper limit on the amount of an individual's human capital. Then, there is an upper limit on the stock of human capital at every moment in any country or region, which is determined by the size and structure of the population. From this point, human capital stock in a country or a region during a period has a maximum growth, which will be defined in this paper as the "human capital stock growth potential" of this country or region in that period, and the purpose of this paper is precisely to estimate China's future human capital growth potential.

Here are some innovations of this paper. First, research contents and ideas are innovative. At present, scholars pay more attention to the estimates of China's human capital stock $[9,13-14]$ and the forecast for the growing speed of China's human stock[10, 15-18]. There are few discussions about the bottleneck of human capital stock growth, which is the core issue to be discussed in this paper. Second, by decomposing the human capital, this paper conducts a certain quantitative analysis to analyze the reasons for the bottleneck of human capital growth speed from the innovative perspective of the change of population age structure. Third, the evaluating method of human capital stock is improved to make results more accurate. Firstly, data on the Status of School completion in the "Data from Households Using Long Form" are utilized, and the impact of changes in the length of schooling on the evaluating results is fully considered. 
Secondly, the setting of the maximum enrolment rate in all levels of education avoids the potential mistake when estimating the enrolment ratio. Thirdly, with the method of the cohort-component population projection, forecasting the average years of education of China's population year by year can help overcome the defect that census data of base year cannot be fully utilized in the five-year forecast every five years.

\section{Measuring Method of Human Capital Stock}

If the growth potential of China's human capital stock needs calculating, then the primary thing is to determine the measuring method. Human capital is easy to define, but it is difficult to measure. At present, there is a quantity of literature on the measurement of human capital stock, but there are three main approaches, namely cost-based approach, income-based approach, and indicators-based approach.

\subsection{Comparative Analysis of Three Approaches for Measuring Human Capital Stock}

\subsubsection{Cost-based approach}

Capital can be regarded as the ability to produce goods and provide services, while investment can be considered as the cost of maintaining or promoting this ability. Capital accumulation is ultimately formed by investment. Generally speaking, in the national economic accounting system, the calculation of the physical capital stock is usually realized by calculating the physical capital investment. Therefore, it is a natural matter to calculate the human capital stock according to the logic of calculating the physical capital. Based on this idea, Kendrick[19] proposed a "permanent inventory method" similar to the calculation of the physical capital stock by calculating the human capital investment cost in detail to calculate human capital stock, and that is what we usually call the "cost-based approach."

Due to the availability of data, it is difficult to use the approach put forward by Kendrick[19] to estimate China's human capital stock without making any changes. However, many scholars have used this idea to study the calculation of China's human capital stock[12, 20]. The key to using the "cost method" to calculate the human capital stock lies in the following points. Firstly, reasonably determine human capital stock at the base period. Secondly, reasonably determine all human capital investment costs. Thirdly, reasonably determine the human capital depreciation rate. Fourth, reasonably determine the price index of human capital investment. The determination of these four points is very subjective. Different studies often use different settings, leading to many studies that adopt the cost-based approach to measure human capital stock, often have very different measured results.

\subsubsection{Income-based approach}

If the "cost-based approach" is based on the reasons for the formation of human capital to measure human capital stock, the "income-based approach" concentrates on the result of the formation of human capital to measure human capital stock. Individuals with different human capital usually have different labor income in which contains human capital information. The fundamental idea of the "income-based approach" is to use labor income to measure human capital stock.

Based on this idea, Weisbrod[21], Jorgenson \& Fraumeni[22], and Mulligan \& Sala-I-Martin[24]have proposed various methods for measuring human capital stock. Chinese scholars[13, 23-24] have separately adjusted the above three methods according to China's actual conditions and measured China's human capital stock. The human capital stock calculated by Wang Dejing et al.[23] and Li Haizheng et al.[13] is measured by monetary value and can be directly compared with the stock of material capital, both of which measure the human capital stock by calculating the present value of the laborers' lifetime earnings. The main differences between the two studies lie in the selection of lifetime earnings subjects, the growth rate of future income, and the different ways of determining the depreciation rate. Zhu Pingfan et al.[24] . However, it only calculates the human capital stock index and does not measure the human capital stock by monetary value.

There will be at least two problems if we adopt an income-based approach. Above all, without relevant statistical data, researchers often rely on a series of assumptions to overcome the insufficiency of statistical data, so the results obtained are less objective. Then, due to the difference in statistical data types and statistical calibers, it is difficult to compare the human capital stock measured by the income-based approach with time and space.

\subsubsection{Indicators-based approach}

Different from the "cost-based approach" and "income-based approach," the core idea of the indicators-based approach supposes that education is the main way to accumulating human capital. Therefore, the approach often uses the indicator of people's educational level as the proxy variable for measuring human capital stock. For instance, literacy rates, international test scores, educational attainment are usually considered proxy variables of human capital stock in lots of literature.

The greatest advantage of the indicators-based approach is that it is simple and easy to understand, the data is easy to collect, the calculation results are more objective, and it is easy to compare horizontally and vertically between countries. Therefore, the "indicator-based approach" is widely used to measure the human capital stock in literature. However, the defect in its theory is distinct. First of all, the approach fails to measure human capital stock formed by other means besides education; secondly, it is hard to precisely measure the disparity of human capital stock caused by educational quality; thirdly, it is difficult to reflect the contribution of different levels of education to the growth of the human capital stock. In addition, the choice of which one or which several 
indicators as the proxy variable of human capital stock also remains a controversy.

\subsection{Definition and Measurement Approach of Human Capital in this Paper}

On the whole, compared with the indicators-based approach, using the "cost-based approach" and the "income-based approach" to measure the human capital stock is more rigorous in theory, but it has unavoidable shortcomings in practical application. Due to the lack of statistical data, the difference in statistical caliber, and the subjective randomness of the premise that needs to be met when calculating human capital, the human capital stock measured by the "cost-based approach" and the "income-based approach" cannot make a horizontal comparison between different countries at the same time and even vertical comparisons between different periods in the same country. Therefore, the data set covering human capital stock in most countries is usually based on the indicators-based approach. The famous Penn World Table 9.0 is a good case in point. It uses the educational years of the population to construct the human capital stock data collection of 182 countries from 1950 to 2014.

Based on the above reasons, this paper intends to employ the indicators-based approach to measure human capital stock and regards the average educational years of the working-age population as the proxy variable of the human capital stock. It must be pointed out that the human capital stock throughout this paper referred to a per capita concept, not a gross concept. In a large number of empirical studies, average educational years are often used as proxy variables for human capital stock, and this paper is no exception. Then, China's human capital stock in the year of $t$ is:

$$
H_{t}=\sum_{I} C_{i}^{t} \cdot E_{i}^{t}
$$

Among them, $i$ means age group, divided into one to ten groups, representing people at the age of 15 to 19,20 to $24, \ldots$, and 60 to 64 , respectively. $C_{i}^{t}$ represents the proportion of the population to working-age population in group $i$ at the year of $t$, reflecting the changes in the age structure of the population; $E_{i}^{t}$ represents the average educational years of the population in group $i$ at the year of $t$, reflecting the changes in age-specific human capital stock.

\section{Decomposition of Human Capital Stock Changes}

From the definition of human capital stock mentioned above, two factors are determining the changes of human capital stock: the first one is the population age structure which to a large extent reflects the distribution of human capital "carriers." Under the condition of a low fertility rate, its changes are hardly affected by government policies; the second is the age-specific human capital stock. It reflects the number of resources one country used for human capital investment. In the case of having large gaps with developed countries, it is subject to changes in government policies. Therefore, the change of the first factor largely determines the development trend of the potential growth rate of human capital stock while that of the second factor largely determines the actual growth rate of human capital stock, which reflects the government's ability to improve the growth of the stock of human capital.

The difference between human capital stock in different periods or different countries can always be interpreted as the difference between these two factors, and the age of other people's capital stock reflects the difference in the growth potential of human capital stock in a country at different times (or between different countries). From this, we can see the difficulty of a country to improve the stock of human capital by increasing investment at different times (or compared to another country). The factor decomposition of the growth rate of human capital is essentially a factor decomposition of the difference in human capital stock in different periods in the same country. This paper tries to help understand the current situation of China's human capital stock by decomposing the growth rate of China's human capital stock from 1950 to 2010 and the differences in human capital stock between China and Japan, China and South Korea, which will show more intuitively the degree of the difficulty for China to improve the stock of human capital with more investment. The reason why South Korea and Japan are compared with China is that Japanese and South Korean cultures are similar to Chinese and that they have a similar process of demographic transition, economic development, and rapid human capital increase, and they all face the similar dilemma of the aging population. Therefore, as developed countries, Japan and South Korea have a certain value for China for their developing experience.

\subsection{Decomposition Method of Human Capital Stock Difference}

Suppose that the stock of human capital in any two different countries (or the stock of human capital in a country at different times) are respectively $H_{A}$ and $H_{B}$, then the difference between the two is:

$$
\Delta H_{A-B}=H_{A}-H_{B}
$$

Substituting Equation (1) into Equation (2), we receive:

$$
\begin{aligned}
& \Delta H_{A-B}=\sum_{i} C_{i}^{A} \cdot E_{i}^{A}-\sum_{i} C_{i}^{B} \cdot E_{i}^{B} \\
& =\frac{\sum_{i} C_{i}^{A} \cdot E_{i}^{A}}{2}+\frac{\sum_{i} C_{i}^{A} \cdot E_{i}^{A}}{2}-\frac{\sum_{i} C_{i}^{B} \cdot E_{i}^{B}}{2}-\frac{\sum_{i} C_{i}^{B} \cdot E_{i}^{B}}{2}+\frac{\sum_{i} C_{i}^{A} \cdot E_{i}^{B}}{2}-\frac{\sum_{i} C_{i}^{A} \cdot E_{i}^{B}}{2}+\frac{\sum_{i} C_{i}^{B} \cdot E_{i}^{A}}{2}-\frac{\sum_{i} C_{i}^{B} \cdot E_{i}^{A}}{2} \\
& =\sum_{i}\left(C_{i}^{A}-C_{i}^{B}\right) \cdot\left[\frac{E_{i}^{A}+E_{i}^{B}}{2}\right]+\sum_{i}\left(E_{i}^{A}-E_{i}^{B}\right) \cdot\left[\frac{C_{i}^{A}+C_{i}^{B}}{2}\right]
\end{aligned}
$$


According to Equation (3), the difference in human capital stock is decomposed into two parts, where $\sum_{i}\left(C_{i}^{A}-C_{i}^{B}\right) \cdot\left[\frac{E_{i}^{A}+E_{i}^{B}}{2}\right]$ is regarded as the influence that the difference of the age structure of the population has on the difference of human capital stock, and $\sum_{i}\left(E_{i}^{A}-E_{i}^{B}\right) \cdot\left[\frac{C_{i}^{A}+C_{i}^{B}}{2}\right]$ is regarded as the influence that the difference of age-specific human capital stock has on the difference of human capital stock. Thus, we define:

$$
\frac{\sum_{i}\left(E_{i}^{A}-C_{i}^{B}\right) \cdot\left[\frac{E_{i}^{A}+E_{i}^{B}}{2}\right]}{\left|\sum_{i}\left(C_{i}^{A}-C_{i}^{B}\right) \cdot\left[\frac{E_{i}^{A}+E_{i}^{B}}{2}\right]\right|+\left|\sum_{i}\left(E_{i}^{A}-E_{i}^{B}\right) \cdot\left[\frac{C_{i}^{A}+C_{i}^{B}}{2}\right]\right|}
$$

the degree of interpretation of the difference of population age structure against the difference of human capital stock, and

$$
\frac{\sum_{i}\left(E_{i}^{A}-E_{i}^{B}\right) \cdot\left[\frac{C_{i}^{A}+C_{i}^{B}}{2}\right]}{\left|\sum_{i}\left(C_{i}^{A}-C_{i}^{B}\right) \cdot\left[\frac{E_{i}^{A}+E_{i}^{B}}{2}\right]\right|+\left|\sum_{i}\left(E_{i}^{A}-E_{i}^{B}\right) \cdot\left[\frac{C_{i}^{A}+C_{i}^{B}}{2}\right]\right|}
$$

the degree of interpretation of the age-specific human capital stock against the difference of human capital stock, in order to reflect the relative influence of the age structure of population and the age-specific human capital stock on the difference of human capital stock.

\subsection{Decomposition Method of Human Capital Stock Difference}

Assuming that time is $\mathrm{t}$ and China's human capital stock is $H_{t}$, then the growth rate of human capital stock is $\Delta H_{t}=H_{t}-H_{t-1}$. We have decomposed China's human capital stock growth rate $\Delta H_{t}$ since 1950 according to the previous method. The data of population age structure is originated from the 2015 Revision of World Population Prospects. The data of age-specific human capital stock is based on Barro and Lee's[10] population years of education data set. Figure 1 shows the decomposition of the growth rate of human capital stock since 1950 in China. The ordinate axis indicates the degree to which different factors explain the growth rate of human capital stock, and the secondary axis indicates the growth rate of human capital stock.

From Figure 1, we can find that: firstly, the change of the age-specific human capital stock is the most important factor to determine China's human capital stock. In various periods, it can explain over $80 \%$ of the increase of China's human capital stock. Secondly, with the proceeding evolution of China's demographic transition, the impact of population age structure change on human capital stock is gradually changing from positive to negative. And since the 1990s, when China's total fertility rate has fallen below the replacement level, the negative impact of population age structure change on the growth of human capital stock is accelerating. Thirdly, since the 1990s, with the increasingly negative impact of population age structure change on the changes in human capital stock, the growth rate of China's human capital stock has gradually declined.

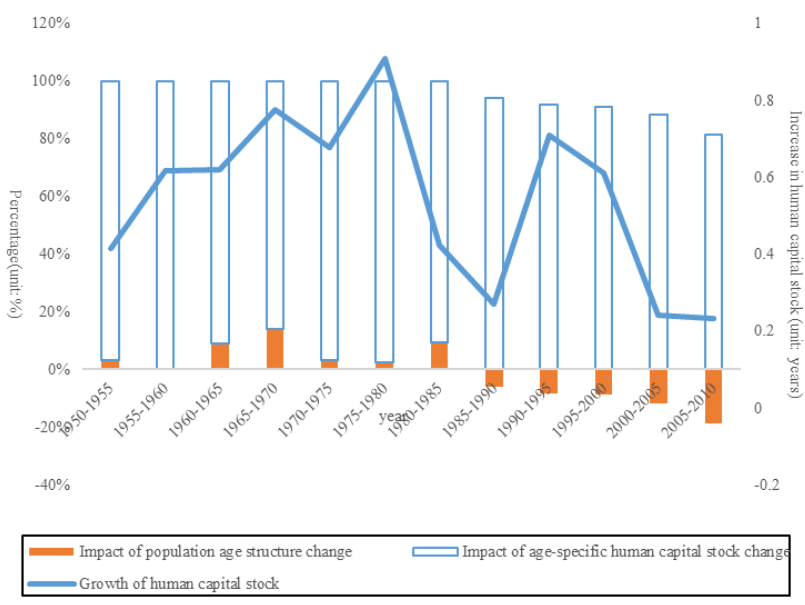

Figure 1: The decomposition of China's human capital stock growth rate since 1950

\subsection{Decomposition of the Difference in Human Capital Stock among China, Japan, and South Korea}

The processes of demographic transition in China, Japan, and South Korea are similar, and the human capital stock in these three countries has experienced a period of rapid growth. However, the processes of how the stock of human capital has increased in these three countries have different characteristics. In order to have a better understanding of the changes in China's human capital stock, the author now compares the changes in China's human capital stock with that of Japan and South Korea. The average age of education for the working-age population in this section is derived from the calculation of Barro and Lee[9]. Regarding the comparison between China and Japan, the average years of education of China's working-age population increased from 6.44 years in 1990 to 8.25 years in 2010 , while that of Japanese increased from 6.86 in 1950 to 8.25 in 1970. In the two different periods above, Japan and China have almost increased the same in human capital stock. Therefore, the author compares the human capital stock in Japan in 1950, $1955,1960,1965$, and 1970 with the human capital stock in China in 1990, 1995, 2000, 2005, and 2010. Regarding the comparison between China and South Korea, the average years of education for the working-age population in South Korea in 1965 are 5.68 years which is similar to that of China with 5.74 years in 1980, and the stock of human capital in China and South Korea after 1980 and 1965 respectively increased very fast. Thus, this paper compares the human capital stock of South Korea in 1965, 1970, 1975, 1980, 1985, 1990, and 1995 with that of China in 1980, 1985, 1990, 1995, 2000, 2005, and 2010. Assuming that the subscript B in Equation (3) represents China and the subscript A represents Japan or South Korea, we decompose the difference in human capital stock according to Equation (3) and reach the results shown in Figure 2, whose data source is the same as that of Figure 1. The abscissa axis in Figure 2 shows the information of the comparison of country types. The main vertical axis shows the degree to which different factors explain human 
capital, and the secondary axis shows the difference in human capital stock.

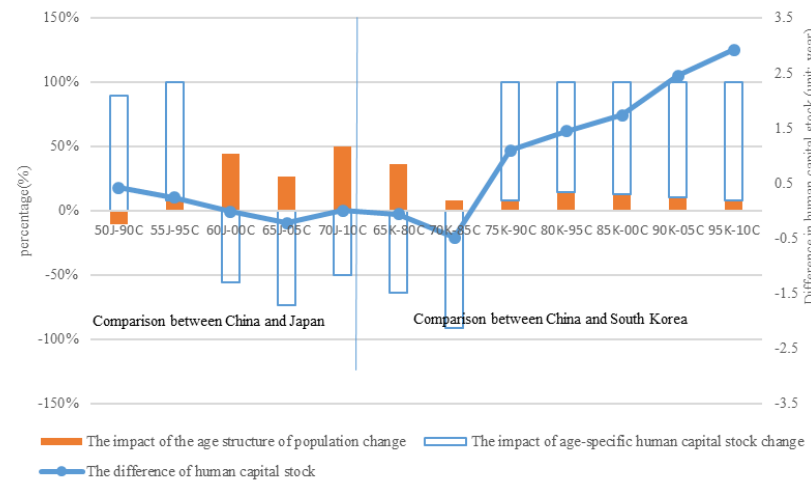

Figure 2: Comparison of human capital stock between China and Japan and South Korea

From the comparison between China and Japan, although their stock of human capital in the corresponding period is almost the same, the influences of population age structure change and age-specific human capital stock change on human capital stock growth in the two countries are different. China relies more on raising the age-specific human capital stock to promote the improvement of human capital, while Japan relies on a younger population age structure (more human capital investment carriers) to enhance its human capital stock with a lower growth speed of age-specific human capital stock than that of China. China's population age structure in 2010 is older than Japan in 1970, meaning that the potential growth rate of China's human capital stock in 2010 is lower than that of Japan in the 1970s. In other words, the current human capital stock in China is more difficult to increase than in Japan in the 1970s. From the comparison between China and South Korea, the change of the age structure of China's population from 1980 to 2010 is similar to that of the South Korean population age structure from 1965 to 1995 . The proportion of the working-age population to the total population is increasing, which means a similar growth rate of human capital stock. However, although China's human capital stock in 1980 is basically the same as South Korea's human capital stock in 1965, the stock of human capital in South Korea after 1965 increases much faster than China's human capital stock after 1980. Obviously, compared with South Korea, China has not fully exploited the potential growth rate of human capital stock.

To sum up, first of all, since the 1990s, the negative impact of the aging of the population on the growth of China's human capital stock has become increasingly serious, and it is increasingly difficult for China to increase the stock of human capital by increasing the age-specific human capital stock. Secondly, according to the comparison with Japan, it can be found that the potential growth rate of China's future human capital is lower than that of the Japanese in a similar stage. Finally, from the comparison with South Korea, it is found that China has not fully exploited the potential of human capital growth in the past and lost some opportunities to increase the stock of human capital quickly. By analyzing the problem of China's future human capital stock growth from the perspective of the potential growth rate of human capital, this paper believes that human capital stock will not necessarily grow rapidly just by increasing investment. In the future, when the aging population accelerates, it still needs further research to see if human capital can continue to increase rapidly.

\section{Decomposition of Human Capital Stock Changes}

The potential for human capital stock growth is the maximum possible increase in human capital stock over a period of time. In terms of the definition for human capital stock in this paper, if each person's years of schooling are limited, then the potential growth of human capital stock depends on population age structure change. Some scholars have predicted the development trend of China's future population education[10, 15-17,]. However, their focus is more on predicting the growth rate of human capital stock but less on the growth potential of human capital stock. The former can be affected by policies of the government, while the latter is less susceptible to them. To grasp the changing trend of the growth potential of human capital stock can contribute to formulating relevant policies. There are two ways to predict the growth rate of human capital stock: firstly, the demographic method of multi-state population projection[15-16]. Secondly, the perpetual inventory method[10, 17]. The biggest difference between them is that the multi-state population projection model assumes that fertility is related to the education level of the population, while the perpetual inventory method does not consider the impact that the education level of the population can have on fertility. This paper holds that in terms of China's current conditions, the fertility rate is mainly affected by family policy. Moreover, when the women's total fertility rate is at a low level, the improvement of population education level can hardly have a substantial impact on the fertility rate of China's population. Furthermore, Barro and Lee[10] compared the prediction results of Samir and Barakat[16] (using a multi-state population prediction model) and the UN World Population Prospects (regardless of the impact of population education level on fertility rate) and found that there is no essential difference between the two estimates of the proportion of the working-age population aged 15-19 in different countries and the proportion of the working-age population aged 20-24. The proportion of these two age groups in the total population is the key to determine the growth of the average population education in the future. Therefore, this paper uses Barro and Lee's[9-10] perpetual inventory method to predict the development trend of China's future human capital stock potential growth rate. Compared with their methods, this paper improves the shortcoming of not considering the school system change over time, so the estimate is more accurate.

\subsection{Estimation Method for the Potential Growth of Human Capital Stock}

\subsubsection{Calculation of human capital stock in the base period}

On the basis of the definition of human capital stock in this paper, before using the perpetual inventory method to 
calculate the growth potential of human capital stock, we first calculate the human capital stock in the base period. The census is a house-to-house survey of China's population and is considered to be the most reliable source of China's population data. Therefore, this paper uses the period of the most recent census as the base period to calculate the human capital stock in 2010 first. In the sixth national population census, the data about the educational level of the population can be divided into two categories: the first category is "Data from All Households," which is derived from the survey of each China's citizen, and the second category is "Data from Households Using Long Form," which is derived from a sample survey of $10 \%$ of the census population and asks for more detailed information than the census. "Data from All Households" only provides information on "national population aged six and over by age, sex and education level," while "Data from Households Using Long Form" also provides information on "Status of School completion." Obviously, it is more accurate to use "Data from Households Using Long Form" to calculate the average years of education for the population. Therefore, this paper prioritizes the use of "Data from Households Using Long Form" first to calculate the human capital stock in 2010. When the "Data from Households Using Long Form" information is insufficient, "Data from All Households" is used.

In the "Data from Households Using Long Form," "Status of School Completion" is divided into: on school graduated, undergraduate, discontinued, and others. By definition of the data, a person whose status of school completion is "graduated" or "school non-completion" has completed all courses and should be considered to have the same years of education, while the person whose status of school completion is "other" does not receive a formal education, the years of schooling is considered to be zero. Therefore, when calculating the years of schooling of the population, it can reclassify the status of school completion of the population into three categories: "on school," "graduated or school non-completion," and "drop out." Besides, length of schooling is the basis for calculating the years of education for the population. From 1966 to 1976, primary school, junior secondary school, and senior secondary school were 5-year, 2-year, and 2-year, respectively. Therefore, in 2010, the people who are 40-49 years old and born in 1960-1969 are considered to be the school system above. After 1986, China passed the "Compulsory Education Law of the People's Republic of China" officially, and nine-year compulsory education began to be implemented. Therefore, in 2010, the population under 30 years old (born after 1980) is a 6-year, 3-year, and 3-year schooling in primary school, junior high school, and senior high school.; In addition to the population of these two age groups, other populations are considered to be 5-year, 3-year, and 3-year of schooling in primary school, junior secondary school, and senior secondary school, respectively.

In the "Data from Households Using Long Form," "Status of School Completion" is divided into: on school graduated, undergraduate, discontinued, and others. By definition of the data, a person whose status of school completion is "graduated" or "school non-completion" has completed all courses and should be considered to have the same years of education, while the person whose status of school completion is "other" does not receive a formal education, the years of schooling is considered to be zero. Therefore, when calculating the years of schooling of the population, it can reclassify the status of school completion of the population into three categories: "on school," "graduated or school non-completion," and "drop out." Besides, length of schooling is the basis for calculating the years of education for the population. From 1966 to 1976, primary school, junior secondary school, and senior secondary school were 5-year, 2-year, and 2-year, respectively. Therefore, in 2010, the people who are 40-49 years old and born in 1960-1969 are considered to be the school system above. After 1986, China passed the "Compulsory Education Law of the People's Republic of China" officially, and nine-year compulsory education began to be implemented. Therefore, in 2010, the population under 30 years old (born after 1980) is a 6-year, 3-year, and 3-year schooling in primary school, junior high school, and senior high school.; In addition to the population of these two age groups, other populations are considered to be 5-year, 3-year, and 3-year of schooling in primary school, junior secondary school, and senior secondary school, respectively.

Due to the different lengths of schooling, the average years of schooling for the population aged 15 to 30 can be calculated firstly. Supposing that $h_{j, k}^{l}$ indicates the education year of the population whose age is $j$, the status of school completion is $l$, and the educational attainment is $k$. Among them, the status of school completion $l$ has the values of $1,2,3$, respectively, means "on school," "graduated or school non-completion" and "drop out "; The values of education attainment $k$ are $0,1,2,3,4,5$, and 6, which means "not going to school," "primary school," "junior secondary school," "senior secondary school," "junior college," "university" and "postgraduate." Supposing that $s_{k}$ represents the maximum number of years of education for an individual with the educational attainment of $k$, then $s_{0}, s_{1}$, $s_{2}, s_{3}, s_{4}, s_{5}, s_{6}$, are 0 years, 6 years, 9 years, 12 years, 15 years, 16 years, 19 years, respectively. If a person can complete all formal education according to the academic system, $m_{j}$ indicates the educational attainment of the person at the age of $j$, then: when $6 \leq j \leq 11, m_{j}=1$; when $12 \leq j \leq 14, m_{j}=2 ;$ When $15 \leq j \leq 17, m_{j}=3$; when $18 \leq j \leq 20 \quad m_{j}=4 \quad$ when $j=21, \quad m_{j}=5$; when $22 \leq j \leq 24, m_{j}=6$; When $j \geq 25, m_{j}=7$; So, when $15 \leq j \leq 30$ the value of $h_{j, k}^{l}$ can be calculated according to the formula of Table 1 . When $31 \leq j \leq 49$, due to the difference in the length of schooling, the value of $h_{j, k}^{l}$ can not be calculated according to Table 1, but the calculation method and the idea are similar. In order to save space, it is omitted here. For the calculation of the population aged 50-64, because the "Data from Households Using Long Form" does 
not give data on the age of the population aged 50-64, therefore, using the "Data from All Households" to calculate the average years of schooling for a population of age $j$.

Table 1: Years of schooling in the population aged 15-30, whose age is $j$, the status of the school is 1 , and the education level is $k$

\begin{tabular}{|c|c|c|c|}
\hline & $k<m_{j}$ & $k=m_{j}$ & $k>m_{j}$ \\
\hline $\boldsymbol{l}=\mathbf{1}$ & $s_{k}$ & $j-6$ & $j-6$ \\
\hline $\boldsymbol{l}=\mathbf{2}$ & $s_{k}$ & $j-6$ & $j-6$ \\
\hline $\boldsymbol{l}=\mathbf{3}$ & $\frac{s_{k-1}+s_{k}}{2}$ & $\frac{s_{k-1}+j-6}{2}$ & $j-6$ \\
\hline
\end{tabular}

Note: .When $18 \leq j \leq 21, h_{j, k=5}^{l=3}=h_{j, k=4}^{l=3}$; when $j \geq 22, h_{j, k=5}^{l=3}=14$.

In summary, assuming an average age of education $h_{j}$ for a population of age $j$, then:

$$
h_{j}=\left\{\begin{array}{ll}
\sum_{l=1} \sum_{k=1} h_{j, k}^{l} \cdot n_{j, k}^{l} & 15 \leq j \leq 49 \\
\sum_{k} n_{j, k} \cdot s_{k}^{j \geq 50}, & 50 \leq j \leq 64
\end{array}\right\}
$$

where $n_{j, k}^{l}$ represents the proportion of the population with the educational attainment of $k$ and the status of the school of $l$, and the population of the age of $j, n_{j, k}$ indicates the proportion of the population with the educational attainment of $k$ to the population of age $j$, and $s_{k}^{j \geq 50}(j \geq 50)$ represents the maximum number of years of education for a population over 50 years of age with the educational attainment of $k$. the values of $s_{1}^{j \geq 50}, s_{2}^{j \geq 50}, s_{3}^{j \geq 50}, s_{4}^{j \geq 50}, s_{5}^{j \geq 50}, s_{6}^{j \geq 50}$, are 5 years, 8 years, 11 years, 14 years, 15 years, and 18 years, respectively. Based on this, we can calculate China's human capital stock in 2010:

$$
H_{2010}=\sum_{j=15}^{j=64} n_{j} h_{j}
$$

Among them, $n_{j}$ is the proportion of the population with age $j$ to the total population. Based on the above method, and combine with the sixth census data of China, it can be calculated that the average years of education for China's population in 2010 is 8.39 years.

4.1.2 Calculation of growth potential of average education year for the age-specific population

The country's investment in education has led to an increase in enrollment, which in turn has led to an increase in the average educational attainment of the population. It is the basic logic for calculating the growth potential of the average years of education. Therefore, when the enrollment rate reaches the maximum, the growth rate of the average years of education for the age-specific population reaches its maximum, which is the growth potential. Getting the maximum value of education enrollment at all levels in China in the future is the key to calculating the growth potential of the average years of education for the population in different age groups. This paper sets the enrollment rate in two scenarios. First, the enrollment rate of education at all levels has reached the limit. That is, the enrollment rate of primary, secondary, senior secondary school, and higher education is $100 \%$. Second, the enrollment rate of education at all levels has reached the average level of developed countries, that is, primary school, secondary school, senior secondary school, and higher education enrollment rates are $100 \%, 100 \%$, $93.4 \%$, and $72.6 \%$, respectively[11, 26]. Higher education includes junior college, undergraduate and postgraduate. The average ratio of colleges and undergraduate students enrolled in $2010-2015$ is $53.41 \%$, while the average proportion of postgraduate students takes up $14.19 \%$ in graduated undergraduates in 2010-2015. When calculating the average growth rate of the years of education in different age groups, it is assumed that these two ratios remain unchanged.

Based on the enrollment rate, the average years of education for the age-specific population in 2015-2100 (at 5-year intervals) can be predicted. Assuming that the time is $t$, the average years of education for the population of age $j$ is $h_{j}^{t}$.

For people aged 30 and over, we assume they have completed all possible formal education at the age of 25 , so, when $j \geq 30, h_{j}^{t}=h_{j-5}^{t-5}$. Therefore, we only need to focus on calculating the average years of education for the population aged between 15 and 29 in 2015-2100. With respect to the prediction of the average years of education for this part of the population, we divide it into two categories: the first category, which was born after 2005, they all received formal education according to the maximum enrollment rate. The second category, which was born before 2005, received formal education under two kinds of enrollment rates. It is relatively simple to calculate the average years of education for the age-specific population in the first category population. We can directly calculate the average years of education for the population aged 15-29 years old under the two kinds of enrollment rates. It can be shown that in the first scenario, based on the maximum enrollment rate, the average age of the 15-29 years old population can be calculated as 9 years, 10 years, 11 years, 12 years, 13 years, 14 years, 15 years, 15.53 years, 15.60 years, 15.68 years, 15.76 years, 15.76 years, 15.76 years, 15.76 years, 15.76 years; In the second option, based on the average enrollment rate of developed countries, the corresponding results are 9 years, 9.93 years, 10.86 years, 11.80 years, 12.48 years, 13.16 years, 13.84 years, 14.19 years, 14.24 years, 14.30 years, 14.35 years, 14.35 years, 14.35 years, 14.35 years, 14.35 years. For the calculation of the average years of education for the age-specific population in the second category, it is more complicated. It needs to be estimated through the age-shift algorithm based on data of the sixth census of China in 2010, that is, $n_{j+5, k}^{t+5, l}$ of time $t+5$ is estimated by $n_{j, k}^{t, l}$ of time $\mathrm{t}$, and then the education year of the corresponding age is calculated according to Table 1 and Equation (4). Here, the key to using the age shift algorithm is to get the number of school populations corresponding to $n_{j, k}^{t, l=1}$ in the first few years of education based on the data in the "Data from Households Using Long Form" of the sixth census. For example, we need to determine the grade of a high school student who is 15 years old in 2010, so that the age-shifting algorithm can be used to estimate the education level of this high school student after 5 years. According to the 
following rules: that is when $k<m_{j}$, the population corresponding to $n_{j, k}^{t, l=1}$ belongs to the last year of the kth level of education; When $k=m_{j}$, the population corresponding to $n_{j, k}^{t, l=1}$ belongs to the grade according to the school system; when $k>m_{j}$, the population corresponding to $n_{j, k}^{t, l=1}$ belongs to the first year of the kth level of education. The logical reason behind it this judgment is to make the years of education of the population aged $\mathrm{j}$ as close as possible to the years of schooling of the population that go to school in a normal school system. It must be pointed out that the above estimation of the age of education for the population aged 15-64-year-old from 2015 to 2100 requires a precondition that the mortality rate of the population born at the same time is irrelevant to the level of education.

4.1.3 Estimation of the population age structure in China from 2015 to 2100

Based on predicting the average years of education $\left(h_{j}\right)$ for the age-specific population in 2015-2100 (at five-year intervals), to predict the average years of education of the population, it is necessary to predict the age structure of the population from 2015 to 2100 years $\left(n_{j}\right)$ first. However, since the most credible demographic data comes from China's census and China's $1 \%$ population sample survey, those population surveys are separated by five years. Due to data availability, it is difficult to predict the age structure of China's population year by year using the common cohort-component population projection. Therefore, it can directly use the results of World Population Prospects, the 2015 Revision's prediction according to the high, medium, and low scenarios. The United Nations-predicted population age structure data is given in the form of age groups (5 years old as a group), that is $C_{i}^{t}$ in Equation (1). Therefore, it is necessary to convert the age structure of the population $\left(C_{i}^{t}\right)$ in the form of age group into the age structure of the population $\left(n_{j}^{t}\right)$ in the form of a single year, to calculate the average years of education for the population over the years. The author uses Sprague's fifth-difference osculatory formula to convert $C_{j}^{t}$ from 2015 to 2100 (at five-year intervals) to $n_{j}^{t}$.

\subsection{Analysis of the Changing Trend of China's Future Human Capital Stock Growth Potential}

Using the above estimation method, the author simulates the trend of China's 2015-2100 human capital stock growth potential under six scenarios. The six scenarios include population prediction high proposal - limit level enrollment rate, population prediction medium proposal - limit level enrollment rate, population prediction low proposal - limit level enrollment rate, population prediction high proposal developed country level enrollment rate, population prediction medium proposal - developed country level enrollment rate and population prediction low proposaldeveloped country level enrollment rate.

Figure 3 shows the simulation results. The following conclusions are: first, we have simulated the changes in the growth potential of human capital stock under the UN's high, medium, and low fertility scenarios. It is undeniable that these scenarios cover the largest possible space for China's future fertility changes. It is not difficult to find out from the curve changes in the graph that there is no significant difference in the growth potential of China's human capital stock under different fertility scenarios, indicating that the future fertility changes have little effect on the potential of China's human capital stock; Second, China's human capital stock still has space for rapid improvement. If the enrollment rate is calculated according to the maximum level, the maximum growth rate of China's working-age population in 2015-2040 may reach 0.77 years per five years. According to the enrollment rate at the level of developed countries, the average growth rate of China's working-age population in 2015-2040 may reach 0.66 years per year, while in the past 20 years, the average growth rate of years of schooling of China's working-age population was 0.5 year per five years. Therefore, China can accumulate human capital at a faster rate than in the past. Third, China's human capital growth potential is indeed worse than that in some other advanced countries that were at a similar stage to China in the past. For example, the average age of education for the working-age population in Korea has risen from 8.61 in 1980 to 13.96 in 2010, with an increase of 0.72 per five years. According to the current development trend of education enrollment at all levels, China's future accumulation of human capital stock is very likely to lag behind South Korea's. Therefore, we should recognize the objective facts and not simply judge that the future human capital in China will grow fast just because of its low stock of human capital.

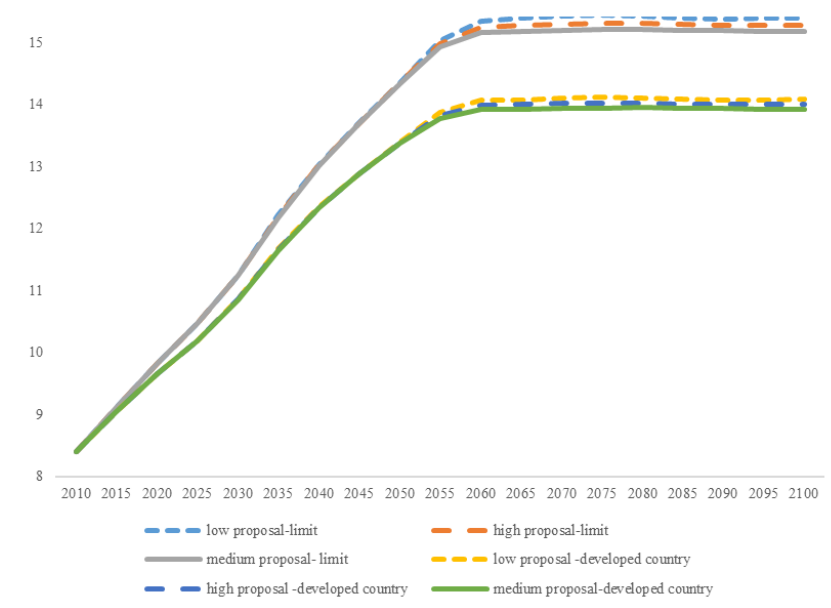

Figure 3: Trends in China's 2015 to 2100 Human Capital Stock Growth Potential

\section{Conclusion}

This paper starts by comparing different methods of measuring human capital and considers that the education index method has the advantages of being easy to calculate, convenient for international comparison, and widely used in various types of research. Therefore, the average age of 
education of the working-age population is selected to measure the human capital stock. By factoring in the growth rate of China's human capital from 1950 to 2010 and the differences in human capital stocks between China, Japan, and South Korea, we found that: First, China's past increase in human capital stock is mainly due to the increase in the human capital stock. Second, the aging population will become a negative factor to China's future human capital accumulation. Third, China has not fully tapped the growth potential of the human capital stock in the past. We use the perpetual inventory method, combined with China's sixth census data, to estimate the trend of the growth potential of China's future human capital stock and judge that China's future human capital accumulation may still accumulate at a faster rate than in the past. Considering the impact of China's transformation, China's human capital accumulation rate is likely to be slower than that of Japan and South Korea, which were at a similar stage with China in the past. Therefore, we cannot be too optimistic that China's future human capital stock can increase rapidly because of the huge gap between the human capital stock of China and developed countries.

From the process of calculating the growth potential of China's human capital stock, it is not difficult to find that in 2040, in the next 20 years, if China cannot fully tap the growth potential of human capital stock in the previous period, the growth potential of human capital in the next period will decrease. In other words, as China's population is becoming increasingly underpopulated, the proportion of young people in the golden age of human capital accumulation in China's total population will continue to decrease, which indicates that future population changes will be increasingly detrimental to China's human capital accumulation. China must recognize the seriousness of the problem. This seriousness is manifested in two aspects: First, the continued increase in pension expenditures caused by the accelerated development of the aging population will squeeze human capital investment resources. Second, under the continued low fertility level in China, the young population who can be used for human capital investment will decrease. Therefore, China needs to race against time and fully exploit the growth potential of human capital stock in each period as much as possible.

\section{Acknowledgement}

This work is supported by School-level Scientific Research Project of Shenzhen Institute of Information Technology (grant number SZIIT2020SK011).

\section{References}

[1] Wang Dewen, Cai Fang, Zhang Xuehui. The savings effect and growth effect of demographic transition. Population Research, 2004, 5: 2-11.

[2] Cai Fang. Demographic Transition, Demographic Dividend and Sustainability of Economic Growth: How Does Full Employment Promote Economic Growth. Population Research, 2004, 28(2): 2-9.
[3] Wang Jinying, Yang Lei. Empirical study on demographic transition, demographic dividend and economic growth in China. Population Journal, 2010, 5: 15-24.

[4] Cai Fang. Demographic Dividends of the Future-Explore the Source of China's Economic Growth. Chinese Population Science, 2009(1): 2-10.

[5] $\mathrm{Hu}$ Anggang, Cai Limin. The Changes in Human Resources Based on the Sixth Census: From Demographic dividend to Human Resources Bonus. Tsinghua Journal of Education, 2011, 32(4): 1-8.

[6] Zhao Yu, Zhong Shuiying, Ren Jingru. Reflection and Redefinition of "Demographic Dividend" in the Process of Economic Development. Journal of Zhongnan University of Economics and Law, 2017(4): 3-11.

[7] Lu Mingtao, Liu Ye. Human Capital Measurement and International Comparison. Chinese Population Science, 2016(3): 55-68.

[8] Zhong Shuiying, Zhao Yu, Ren Jingru. Research on the Substitution of Education Dividend for Demographic Dividend. Chinese Population Science, 2016(2): 26-34.

[9] Barro R J, Lee J W. A new data set of educational attainment in the world, 1950-2010. Journal of development economics, 2013, 104: 184-198.

[10] Barro R J, Lee J W. Education matters: Global schooling gains from the 19th to the 21st century. Oxford University Press, 2015.

[11] Brian K. OECD Insights Human Capital How what you know shapes your life: How what you know shapes your life. OECD publishing, 2007.

[12] Zhang Fan. China's physical and human capital estimates. Economic Research, 2000(8): 65-71.

[13] Li Haizheng, Liang binling, Barbara Fraumeni, Liu Zhiqiang, Wang Xiaojun. China's Human Capital Measurement and Index Construction. Economic Research Journal, 2010, 45(08): 42-54.

[14] Lutz W, Goujon A, KC S, et al. Reconstruction of populations by age, sex and level of educational attainment for 120 countries for 1970-2000. Vienna yearbook of population research, 2007: 193-235.

[15] Zheng Xiaoying, Chen Gong, Pang Lihua, et al. Future Population and Human Capital in China. Population and Development, 2007(01): 1-11+72.

[16] Samir K C, Barakat B, Goujon A, et al. Projection of populations by level of educational attainment, age, and sex for 120 countries for 2005-2050. Demographic research, 2010, 22: 383-472.

[17] Ahuja V, Filmer D. Educational attainment in developing countries: New estimates and projections disaggregated by gender. Available at SSRN 614964, 1995.

[18] Caselli F, Ciccone A. The human capital stock: a generalized approach: comment. American Economic Review, 2019, 109(3): 1155-74.

[19] Kendrick J W. Front matter, The Formation and Stocks of Total Capital//The Formation and Stocks of Total Capital. NBER, 1976: -28-0.

[20] Jiao Binlong, Jiao Zhiming. Estimation of China's Human Capital Stock from 1978-2007. Economist, 2010, 9(9): 27-33.

[21] Weisbrod B A. The valuation of human capital. Journal of Political Economy, 1961, 69(5): 425-436. 
[22] Jorgenson D W, Fraumeni B M. Investment in education and US economic growth. The Scandinavian Journal of Economics, 1992: S51-S70.

[23] Wang Dejing, Liu Jinshi, Xiang Rongmei. Estimation of China's Human Capital Stock: Based on the Income Method. Journal of Statistics and Information, 2006, 21(5): 68-74.

[24] Zhu Pingfang, Xu Dafeng. Estimation of human capital in Chinese cities. Economic Research, 2007(9): 84-95. 